\title{
Risk factors for diabetes mellitus by age and sex: results of the National Population Health Survey
}

\author{
B. C.K.Choi ${ }^{1,2}$, F.Shi ${ }^{2}$ \\ ${ }^{1}$ Surveillance and Risk Assessment Division, Centre for Chronic Disease Prevention and Control, Health Canada, Ottawa, \\ Ontario, Canada \\ ${ }^{2}$ Department of Epidemiology and Community Medicine, Faculty of Medicine, University of Ottawa, Ottawa, Ontario, Canada
}

\section{Abstract}

Aims/hypothesis. We aimed to assess the risk factors for diabetes mellitus, by age and sex in Canada and to recommend prevention and control strategies.

Methods. This study was based on the Canadian 1996-1997 National Population Health Survey which comprised 69494 participants aged 12 years and over. The prevalence of diabetes mellitus was analysed in relation to age, sex, body mass index, overweight status, energy expenditure, physical activity, smoking, drinking, income, marital status, education and rural or urban residence.

Results. The prevalence of diabetes increased with age and body mass index and increased inversely with energy expenditure in both males and females. Current and former smokers were associated with a higher prevalence of diabetes. No effect was observed in regular or former drinkers. Prevalence of diabetes increased inversely with income, especially among women. Women who were single and 35 to 64 years old had a higher prevalence of diabetes than women of the same age who were married. The prevalence of diabetes was not found to be related to the level of education. Urban or rural residence was not found to have an effect on the prevalence of diabetes.

Conclusion/interpretation. Women and men of all ages should avoid becoming overweight, by maintaining their body mass index below $25 \mathrm{~kg} / \mathrm{m}^{2}$ and $27 \mathrm{~kg} /$ $\mathrm{m}^{2}$, respectively. They should maintain a moderate level of physical activity. Patients with diabetes should give up smoking completely. Diabetes prevention and control strategies should be targeted for women in low income groups. [Diabetologia (2001) 44: 1221-1231]

Keywords Risk factors, diabetes mellitus, population health, prevalence.
Diabetes mellitus ranks as the seventh leading cause of death in Canada [1]. It is estimated that 1.2 to 1.4 million Canadians aged 12 and older are currently

Received: 8 November 2000 and in revised form: 30 May 2001

Corresponding author: Dr. Bernard C.K.Choi, Surveillance and Risk Assessment Division, Centre for Chronic Disease Prevention and Control, Health Canada, PL\#1918C3, Tunney's Pasture, Ottawa, Ontario, Canada K1A 0K9. E-mail: Bernard_Choi@hc-sc.gc.ca

Abbreviations: CAI, Computer-assisted interview; EE, energy expenditure; MET, metabolic energy cost; NHIS, National Health Interview Survey; NPHS, National Population Health Survey; OR, odds ratio; RR, relative risk; SPSS, Statistical Package for Social Sciences living with diabetes (prevalence of 4.9-5.8\%), although only about 800000 of them are diagnosed cases [1]. In addition, diabetes is diagnosed in an estimated 60000 Canadians every year [1]. National health surveys in Canada show an increasing prevalence rate of self-reported diabetes, from $2.5 \%$ in 1978 (Canada Health Survey) to 3.2\% in 1996 (National Population Health Survey, NPHS) [1]. The prevalence of diabetes is also increasing in the United States, from $0.9 \%$ in 1958 to $3.1 \%$ in 1993 (National Health Interview Survey, NHIS) [2]. This increase has been suggested to result from an ageing population and an increasing prevalence of people who are obese and who are not physically active [3]. However, these suggestions have not been confirmed. 
The National Population Health Survey (NPHS) is conducted by Statistics Canada which started in 1994-95 (Cycle 1) and is repeated every two years for a period of up to two decades [4]. This is the largest population health survey to date in Canada. Along with cross-sectional information, the survey collects longitudinal data for a panel of subjects [5].

This study is an analysis of the NPHS Cycle 2 data collected from June 1996 to August 1997. It describes and documents the effects of obesity, physical inactivity and other potential risk factors, such as smoking and drinking, on diabetes in Canada, by age and sex. Based on our results a number of recommendations for the prevention and control of diabetes have been made.

\section{Subjects and methods}

Data for this study were extracted from NPHS 1996-1997, Health Share File (cross-sectional data). This was the most recent data available, as the 1998-1999 NPHS data was still being collected at the time of this study. It was a stratified sample and therefore representative of the Canadian population (using weighted procedures in analysis). NPHS was approved by an ethics committee and study participants gave their informed consent. Data were collected by computer-assisted interview (CAI) by telephone ( $95 \%$ of interviews) and in person (5\%). The overall response rate was $83 \%$. The outcome variable (having diabetes or not) was based on the answer of respondents to the question "Do you have diabetes?" A participant was considered as having diabetes if the self-reported answer was "Yes" and not having diabetes if the answer was "No". Respondents younger than 12 years old were excluded from the analysis. The diabetes cases in this study were prevalent cases in 1996 to 97.

The potential risk factors studied for diabetes included age, sex, BMI, energy expenditure (EE), smoking, drinking, income, marital status, education, and rural or urban residence.

Body mass index was calculated for persons 20 to 64 years old, excluding pregnant woman, or anyone less than $92 \mathrm{~cm} \mathrm{(3}$ feet) or $2.13 \mathrm{~m}$ (7 feet) and over. BMI was calculated, based on the self-reported weight and height, as the weight in kilograms divided by the square of height in metres [6]:

BMI $\left(\mathrm{kg} / \mathrm{m}^{2}\right)=$ Weight $(\mathrm{kg}) /[\text { Height }(\mathrm{m})]^{2}$.

Four categories of body weight based on BMI were considered: insufficient weight, BMI less than 20; acceptable weight, BMI from 20 to less than 25; some excess weight, BMI from 25 to 27; overweight, BMI greater than 27.

Energy expenditure (EE) was calculated using the frequency and time per session of the physical activity as well as its MET value. The MET is a value of metabolic energy cost expressed as a multiple of the resting metabolic rate, obtained from a table provided by Statistics Canada. Thus, an activity of 4 METS, e.g. bicycling, requires four times the amount of energy required when the body is at rest.

$\mathrm{EE}\left(\mathrm{kcal} \cdot \mathrm{kg}^{-1} \cdot \mathrm{day}^{-1}\right)=\Sigma\left[\left(\mathrm{N}_{\mathrm{i}} * \mathrm{D}_{\mathrm{i}} * \mathrm{MET}\right) / 365\right]$,

where $\mathrm{N}=$ number of times respondents engaged in an activity i over a 12 -month period,

$\mathrm{D}=$ the average duration in hours of the activity $\mathrm{i}$, and
MET $=$ the energy cost of the activity expressed as kilocalorie expended per kilogram of body weight per hour of activity, $\mathrm{kcal} \cdot \mathrm{kg}^{-1} \cdot \mathrm{h}^{-1}$, divided by 365 to convert yearly data into daily data.

Three categories of physical activity based on EE were considered: active, EE 3 or greater; moderate, EE from 1.5 to less than 3 ; inactive, EE less than 1.5.

Six categories of smokers were considered: never smoker, former occasional smoker, always an occasional smoker, occasional smoker but former daily smoker, daily smoker $(1+$ cigarettes/day), former daily smoker.

Four categories of drinkers were considered: abstinent (never drank), occasional drinker (less than one drink a month), regular drinker (a drink at least once a month), former drinker (did not have a drink in the last 12 months).

Income adequacy was based on household income and the size of the household, according to a table provided by Statistics Canada. Five categories of income adequacy were considered: lowest income, lower middle income, middle income, upper middle income, and highest income. For example, lowest income included households with less than $\$ 10,000$ Canadian dollars (with 1 to 4 persons) or less than $\$ 15,000$ (with 5 or more persons), and highest income included households with $\$ 60,000$ or more (with 1 or 2 persons) or $\$ 80,000$ or more (with 3 or more persons).

Seven categories of marital status were considered: single (never married), living with a partner, common-law, now married, separated, divorced, widowed.

Education was based on the highest number of years of schooling successfully completed. Four categories of education were considered: no or some schooling, secondary school, beyond high school, college or university degree.

Urban residence referred to residence in urban areas, i.e. those continuously built-up areas having a population concentration of 1000 or more and a population density of 400 or more per square kilometre based on previous census. Residence in other areas were considered rural.

Data analysis was carried out using SPSS (Statistical Package for Social Sciences; http://www.spss.com). In the analysis, data were cross-tabulated to determine the prevalence of diabetes in different risk factor categories, by age and sex. Because of the stratified sampling used in the NPHS, weighted prevalence of diabetes were calculated using an expansion weight variable (WT66) to make the survey sample data standardized to the 1996 Canadian population. Bar charts were made using Harvard Graphics (http://www.harvardgraphics. com) to illustrate the different levels of prevalence of diabetes in different risk factor categories, by age and sex. Test of significance and estimation of the odds ratio (OR) were done by logistic regression. Multiple logistic regression was used to study multiple risk factor associations which could be inter-correlated and to adjust for potential confounding. A $p$ value of 0.05 (two-sided) was considered to be statistically significant.

\section{Results}

In the NPHS health share file, of the 77403 subjects interviewed, 7879 who were less than 12 years old and 30 respondents who did not answer the diabetes question, were deleted from this analysis, leaving 69494 subjects. Of these, there were 2529 prevalent cases of diabetes and 66965 subjects with no self-reported diabetes. The prevalence of diabetes in this 
Table 1. Odds ratios (OR), $p$ values and $95 \%$ confidence intervals (CI) for diabetes from univariate and multi-variate logistic regression models, National Population Health Survey, Canada 1996-1997

\begin{tabular}{|c|c|c|c|c|c|c|}
\hline \multirow[t]{2}{*}{ Risk variables } & \multicolumn{3}{|c|}{ Univariate models $^{\mathrm{a}}$} & \multicolumn{3}{|c|}{ Multivariate model ${ }^{\mathrm{b}}$} \\
\hline & OR & $p$ value & $95 \% \mathrm{CI}$ & OR & $p$ value & $95 \% \mathrm{CI}$ \\
\hline 1. Age at diagnosis & 1.06 & 0.00 & $1.05-1.06$ & 1.09 & 0.00 & $1.08-1.09$ \\
\hline $\begin{array}{l}\text { 3. Body mass index }(\mathrm{BMI}) \\
\text { Overweight }\left(\mathrm{BMI}>27 \mathrm{~kg} / \mathrm{m}^{2}\right) \\
\text { Some excess weight }\left(\mathrm{BMI} 25-27 \mathrm{~kg} / \mathrm{m}^{2}\right) \\
\text { Acceptable weight }\left(\mathrm{BMI} 20-25 \mathrm{~kg} / \mathrm{m}^{2}\right) \\
\text { Insufficient weight }\left(\mathrm{BMI}<20 \mathrm{~kg} / \mathrm{m}^{2}\right)\end{array}$ & $\begin{array}{l}3.86 \\
1.60 \\
1.00 \\
0.60\end{array}$ & $\begin{array}{l}0.00 \\
0.00 \\
0.01\end{array}$ & $\begin{array}{l}3.33-4.49 \\
1.31-1.94\end{array}$ & $\begin{array}{l}2.97 \\
1.44 \\
1.00 \\
0.92\end{array}$ & $\begin{array}{l}0.00 \\
0.00\end{array}$ & $\begin{array}{l}2.50-3.53 \\
1.15-1.80 \\
0.61-1.40\end{array}$ \\
\hline $\begin{array}{l}\text { 4. Energy expenditure }(\mathrm{EE}) \\
\text { Inactive }(\mathrm{EE}<1.5 \mathrm{kcal} / \mathrm{kg} / \mathrm{day}) \\
\text { Moderate }(\mathrm{EE} 1.5-2.9 \mathrm{kcal} / \mathrm{kg} / \mathrm{day}) \\
\text { Active }(\mathrm{EE}>3.0 \mathrm{kcal} / \mathrm{kg} / \text { day })\end{array}$ & $\begin{array}{l}1.77 \\
1.16 \\
1.00\end{array}$ & $\begin{array}{l}0.00 \\
0.07\end{array}$ & $\begin{array}{l}1.56-2.02 \\
0.99-1.36\end{array}$ & $\begin{array}{l}1.16 \\
1.29 \\
1.00\end{array}$ & $\begin{array}{l}0.15 \\
0.03\end{array}$ & $\begin{array}{l}0.95-1.42 \\
1.02-1.62\end{array}$ \\
\hline $\begin{array}{l}\text { 5. Type of smoker } \\
\text { Former daily smoker } \\
\text { Current daily smoker (smoke at least } 1 \text { cigarette a day) } \\
\text { Occasional smoker but former daily smoker } \\
\text { Always an occasional smoker } \\
\text { Former occasional smoker } \\
\text { Never smoked }\end{array}$ & $\begin{array}{l}2.28 \\
0.98 \\
0.43 \\
0.47 \\
0.70 \\
1.00\end{array}$ & $\begin{array}{l}0.00 \\
0.74 \\
0.00 \\
0.00 \\
0.00\end{array}$ & $\begin{array}{l}2.06-2.53 \\
0.87-1.11 \\
0.26-0.73 \\
0.29-0.76 \\
0.56-0.87\end{array}$ & $\begin{array}{l}1.39 \\
1.63 \\
0.80 \\
0.80 \\
1.26 \\
1.00\end{array}$ & $\begin{array}{l}0.00 \\
0.00 \\
0.55 \\
0.58 \\
0.16\end{array}$ & $\begin{array}{l}1.16-1.67 \\
1.35-1.96 \\
0.60-1.63 \\
0.35-1.79 \\
0.91-1.74\end{array}$ \\
\hline $\begin{array}{l}\text { 6. Type of drinker } \\
\text { Former drinker (did not have a drink in the past } \\
12 \text { months) } \\
\text { Regular drinker (a drink at least once a month) } \\
\text { Occasional drinker (less than one drink a month) } \\
\text { Abstinent (never drank) }\end{array}$ & $\begin{array}{l}1.85 \\
0.59 \\
0.80 \\
1.00\end{array}$ & $\begin{array}{l}0.00 \\
0.00 \\
0.00\end{array}$ & $\begin{array}{l}1.60-2.14 \\
0.52-0.68 \\
0.69-0.94\end{array}$ & $\begin{array}{l}1.11 \\
0.45 \\
0.69 \\
1.00\end{array}$ & $\begin{array}{l}0.45 \\
0.00 \\
0.00\end{array}$ & $\begin{array}{l}0.85-1.43 \\
0.35-0.58 \\
0.53-0.90\end{array}$ \\
\hline 7. Income adequacy ( 5 categories $)^{\mathrm{c}}$ & 1.29 & 0.00 & $1.24-1.35$ & 1.21 & 0.00 & $1.13-1.30$ \\
\hline $\begin{array}{l}\text { 8. Marital status } \\
\text { Widowed } \\
\text { Divorced } \\
\text { Separated } \\
\text { Now married } \\
\text { Common-law / live with a partner } \\
\text { Single }\end{array}$ & $\begin{array}{l}9.42 \\
3.39 \\
3.92 \\
3.58 \\
1.11 \\
1.00\end{array}$ & $\begin{array}{l}0.00 \\
0.00 \\
0.00 \\
0.00 \\
0.52\end{array}$ & $\begin{array}{l}7.93-11.20 \\
2.69-4.28 \\
2.97-5.18 \\
3.11-4.13 \\
0.81-1.51\end{array}$ & $\begin{array}{l}0.84 \\
0.66 \\
0.66 \\
0.74 \\
0.79 \\
1.00\end{array}$ & $\begin{array}{l}0.38 \\
0.01 \\
0.07 \\
0.01 \\
0.20\end{array}$ & $\begin{array}{c}0.57-1.24 \\
0.48-0.91 \\
0.43-1.03 \\
0.59-0.92 \\
0.55-1.13\end{array}$ \\
\hline
\end{tabular}

a10 univariate models with one risk variable in each logistic regression model.

b 1 multivariate model with 10 risk variables in the logistic regression model.

c5 income categories:

$5=$ lowest income $:<\$ 10,000$ (1 to 4 persons in household); $<\$ 15,000$ (5 or more persons)

4 = lower middle income: $\$ 10,000$ to $\$ 14,999$ (1 or 2 persons); $\$ 10,000$ to $\$ 19,999$ (3 or 4 persons); $\$ 15,000$ to $\$ 29,999$ (5 or more persons)

3 = middle income: $\$ 15,000$ to $\$ 29,999$ (1 or 2 persons); $\$ 20,000$ to $\$ 39,999$ (3 or 4 persons); $\$ 30,000$ to $\$ 59,999$ (5 or more persons)

sample of Canadians aged 12 years and over was $3.2 \%$ (1996).

Age and sex. Weighted prevalence of diabetes increased with age, from $0.5 \%$ in the 12 to 34 year age group to about 10 to $14 \%$ in the 75 and older age group. The odds of diabetes increased by $9 \%$ (multivariate model) per year increase in age (Table 1$)$. Males, almost in all age groups, had a higher prevalence of diabetes than females. The only exception
2 = upper middle income: $\$ 30,000$ to $\$ 59,999$ (1 or 2 persons); $\$ 40,000$ to $\$ 79,999$ ( 3 or 4 persons); $\$ 60,000$ to $\$ 79,999$ ( 5 or more persons),

1 = highest income: $\$ 60,000$ or more ( 1 or 2 persons); $\$ 80,000$ or more ( 3 or more persons).

d4 education categories:

$4=$ no schooling, elementary school or some secondary school.

$3=$ secondary school graduation.

2 = beyond high school, some trade school, some community college.

$1=$ college or university degree

was in the 35 to 44 age group, in which males had a slightly lower prevalence $(1.1 \%)$ than females $(1.5 \%)$ (data not shown). The overall odds ratio for diabetes was 1.44 comparing males with females, after adjusting for a number of potential confounders (Table 1).

Body mass index. In general, prevalence of diabetes was found to increase with BMI in males and females (Table 1). For example, prevalence of diabetes was 


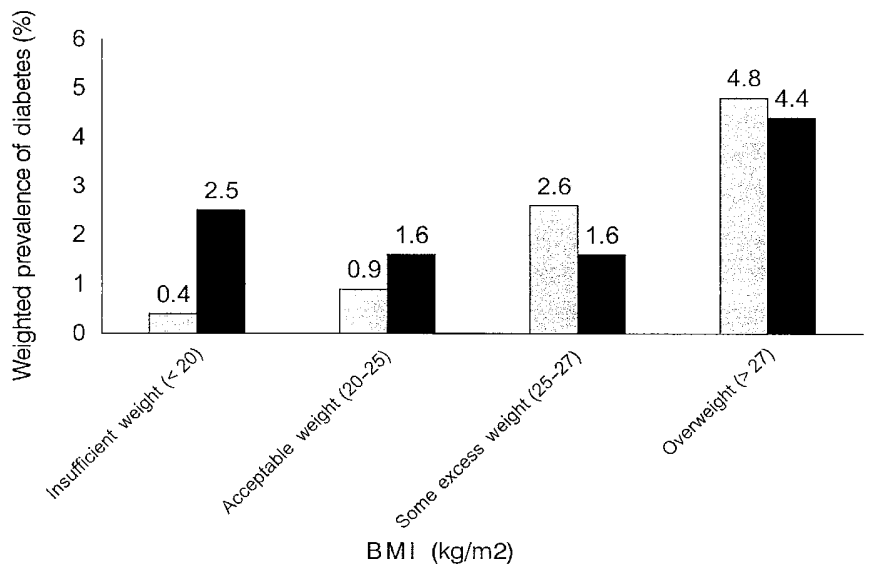

Fig. 1. Diabetes prevalence by body mass index and sex, Canada, 1996-1997 ( $n=47824)$; female $(\square)$, male $(\square)$

higher for those males with BMI greater than 27 (4.4\%) compared to males with acceptable BMI of 20 to $25(1.6 \%)$ and for those females with BMI greater than 27 (4.8\%) compared to females with acceptable BMI (0.9\%) (Fig. 1). Moreover this increase was found to be more readily detectable among females than males. For example, the some excess weight group (BMI from 25 to 27) in females showed an increase in prevalence of diabetes $(2.6 \%)$ compared with the reference group $(0.9 \%)$ but there was no observable difference in prevalence of diabetes in males in these two groups (both 1.6\%) (Fig. 1). The males only showed an increased prevalence in the overweight group (BMI greater than 27). The insufficient weight group (BMI less than 20) in males had a higher prevalence of diabetes $(2.5 \%)$ than the reference group $(1.6 \%)$ that had a higher BMI of 20 to 25 (Fig. 1). However, a closer investigation of the profile of these men with insufficient weight who also have diabetes indicated that the average age of this group (52 years) is substantially older than the average age of all men with insufficient weight (36 years). When adjusted for age and other potential confounding factors, the effect of the insufficient weight group disappeared and became statistically non-significant $(\mathrm{OR}=0.92, p=0.71)$ (Table 1$)$.

When BMI was dichotomized into overweight (BMI greater than 27) and not overweight (BMI less than or equal to 27), the overweight group consistently had a higher prevalence of diabetes in both males and females, in all age groups, than the not overweight group (Fig. 2). In Figure 2 the 12 to 19 year and 65 or older year age groups were excluded, as BMI was only calculated in the NPHS for persons 20 to 64 years old.

Energy expenditure (EE). In both males and females, there was an increase in the prevalence of diabetes with a decrease in energy expenditure (Fig.3). According to the calculations for $\mathrm{EE}$, a decrease in ener-

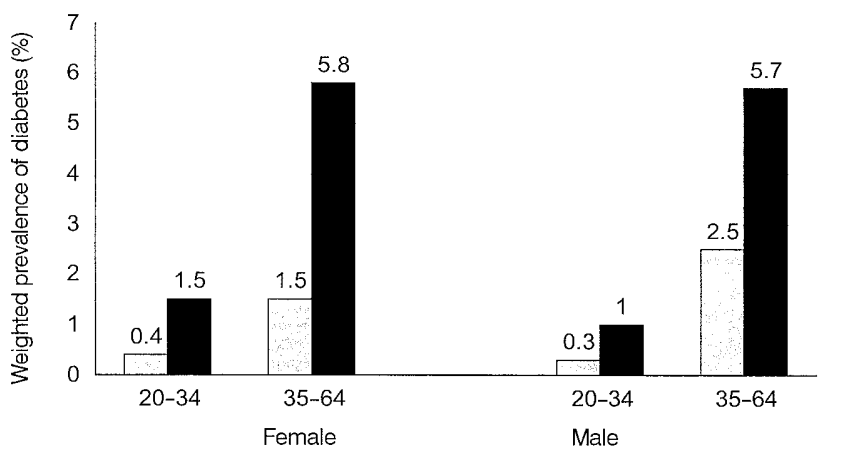

Fig. 2. Diabetes prevalence by overweight status, age and sex, Canada, 1996-1997 ( $n=47824)$; not overweight $(\square)$, overweight (ם); Overweight: BMI > 27

gy expenditure means a decrease in the frequency, duration, and/or energy requirement of physical activity. For example, inactive males had a higher prevalence of diabetes $(4.0 \%)$ than active males $(2.6 \%)$ and inactive females had a higher prevalence of diabetes $(3.5 \%)$ than active females (1.6\%) (Fig. 3 ).

When EE was dichotomized and studied in different age groups, the benefit of physical activity was observed in females in all age groups but in males only in the older age groups (65+ years). For example in the 65 or older year age group, the prevalence of diabetes was $8.2 \%$ in the active group and $15.3 \%$ in the inactive group for males, and $6.5 \%$ in the active group and $10.0 \%$ in the inactive group for females (Fig. 4). For the younger males, there was no observable benefit of physical activity. For example, in the men aged 35 to 64 years, prevalence of diabetes was slightly higher in the active group $(3.8 \%)$ than the inactive group (3.6\%) (Fig. 4).

Smoking. A small adverse effect of daily smoking on diabetes was observed in men but not in women. For example, male daily smokers had a higher prevalence of diabetes $(2.9 \%)$ than male never smokers $(2.3 \%)$, but female daily smokers did not have a higher prevalence $(2.2 \%)$ than female never smokers $(2.9 \%)$ (Fig.5). Former smoking was associated with a high prevalence of diabetes in both men and women ( $7.0 \%$ and $4.3 \%$, respectively) when compared to daily smokers $(2.9 \%$ and $2.2 \%$ for men and women, respectively) or never smokers $(2.3 \%$ and $2.9 \%)$ (Fig. 5).

Current daily smokers and former smokers, when grouped together, had a higher prevalence of diabetes in men in all age groups (Fig. 6). However, for women, current and former smoker did not show an increase in the prevalence in diabetes in the very old (65 + year) and the very young (12-34 year) age groups (Fig. 6).

In multivariate logistic regression with adjustment for other possible confounders such as age, sex and income, current daily smoker was found to have the 


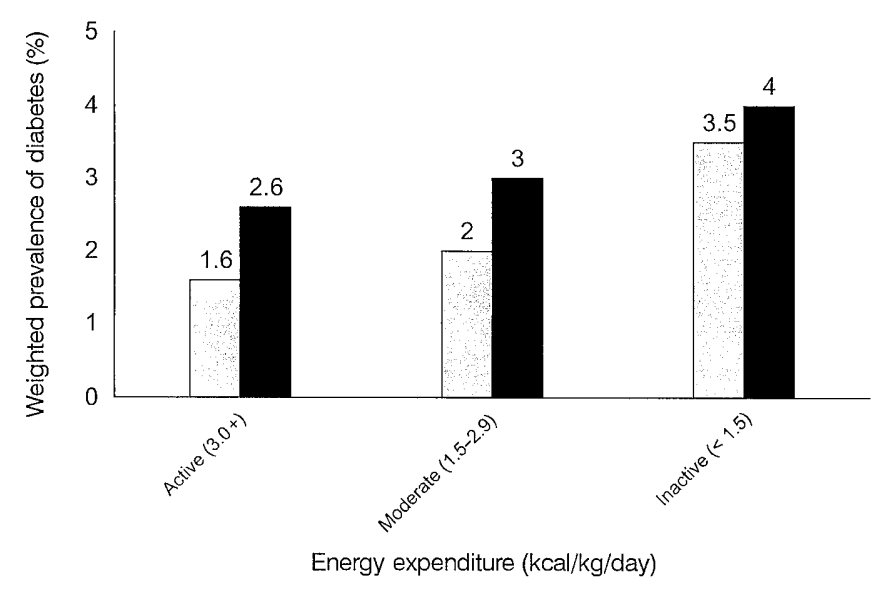

Fig.3. Diabetes prevalence by energy expenditure and sex, Canada, 1996-1997 $(n=67666)$; female $(\square)$, male (

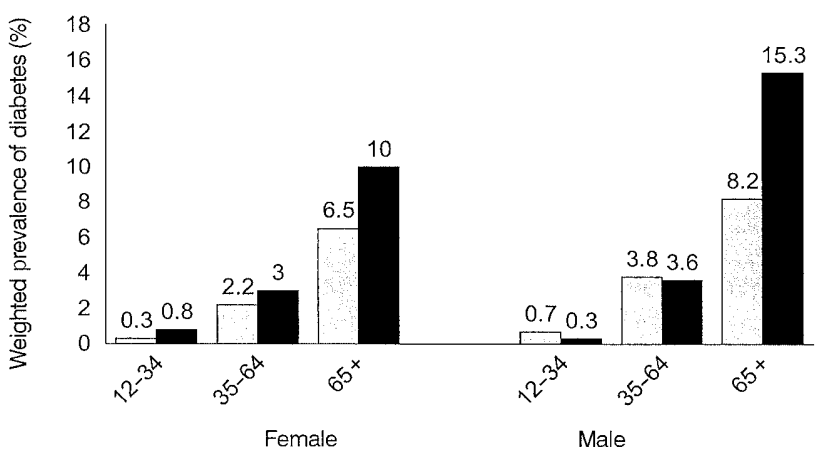

Fig. 4. Diabetes prevalence by physical activity status, age and sex, Canada, 1996-1997 $(n=67666)$; active $(\square)$, inactive $(\square)$; Inactive: energy expenditure $<1.5 \mathrm{kcal} / \mathrm{kg} /$ day

largest odds ratio for diabetes $(\mathrm{OR}=1.63, p=0.00)$, followed by former daily smoker $(\mathrm{OR}=1.39$, $p=0.00)$ (Table 1).

Drinking. Drinking was associated with diabetes in men but not women. In males, occasional drinkers $(3.9 \%)$, regular drinkers $(3.0 \%)$ and former drinkers $(6.9 \%)$ all had a higher prevalence of diabetes than abstainers $(2.1 \%)$. However, in women, the regular drinkers group was associated with the lowest prevalence of diabetes $(1.2 \%)$ when compared to the other drinking groups $(2.5 \%$ to $6.5 \%)$. In both men and women, former drinkers were associated with the highest prevalence of diabetes $(6.9 \%$ and $6.5 \%$, respectively).

When considered by age, the effect of drinking on diabetes was inconsistent in various age groups. Former or regular drinkers were associated with a higher prevalence of diabetes than the other drinkers only among those 65 years or older, and this effect was small. For example, among those 65 or older, male former or regular drinkers had a slightly higher prevalence $(12.3 \%)$ than the other drinkers $(11.3 \%)$, and

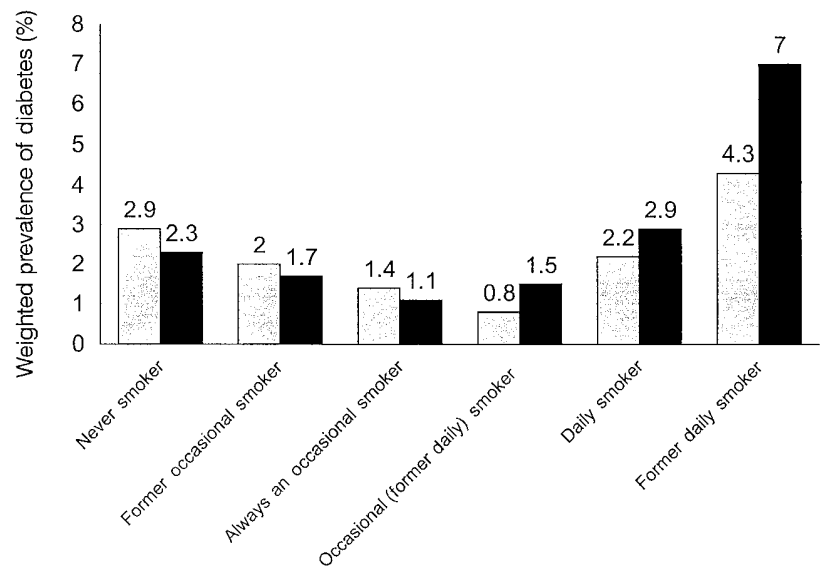

Fig. 5. Diabetes prevalence by type of smoking and sex, Canada, 1996-1997 ( $n=69336)$; female $(\square)$, male $(\square)$

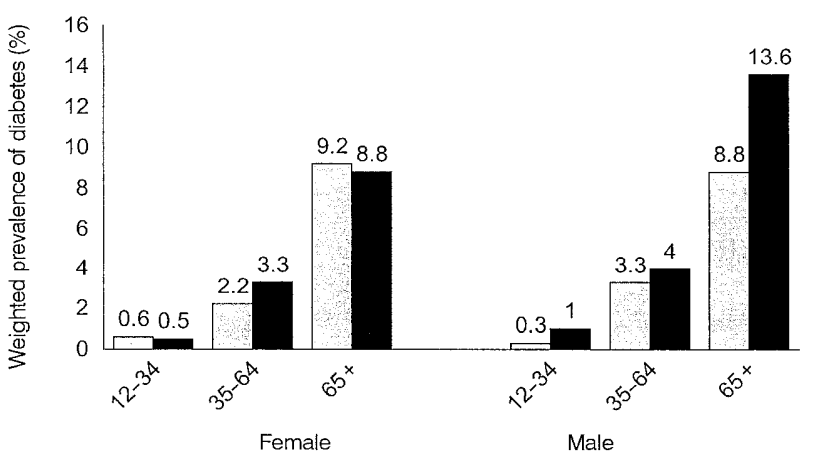

Fig. 6. Diabetes prevalence by smoking status, age and sex, Canada, 1996-1997 $(n=69336)$; occasional or non-smoker $(\square)$, former or daily smoker ( $\square)$; Daily Smoker: smoke at least 1 cigarette a day

female former or regular drinkers had a slightly higher prevalence $(9.3 \%)$ than the other drinkers $(8.9 \%)$. However, this effect of drinking was not observed in the age groups younger than 65 years. In our multivariate logistic regression analysis no association was found between drinking and diabetes (Table 1).

Income. Low income in general tended to be associated with a high prevalence of diabetes, in both males and females (Table 1). However, a statistically significant linear trend was found only in females $(p<0.05)$ (data not shown). In males, the highest income and the lowest income groups were associated with a reduced prevalence of diabetes compared to the middle or lower middle income groups (Fig. 7).

When the two lowest income groups were combined together as the inadequate income group and studied by age, it was found that although inadequate income increased the prevalence of diabetes, this was not observed among men 65 years or older. In these men, the inadequate income group had a lower prevalence of diabetes $(7.9 \%)$ than the higher, adequate income group (13.9\%) (Fig. 8). 


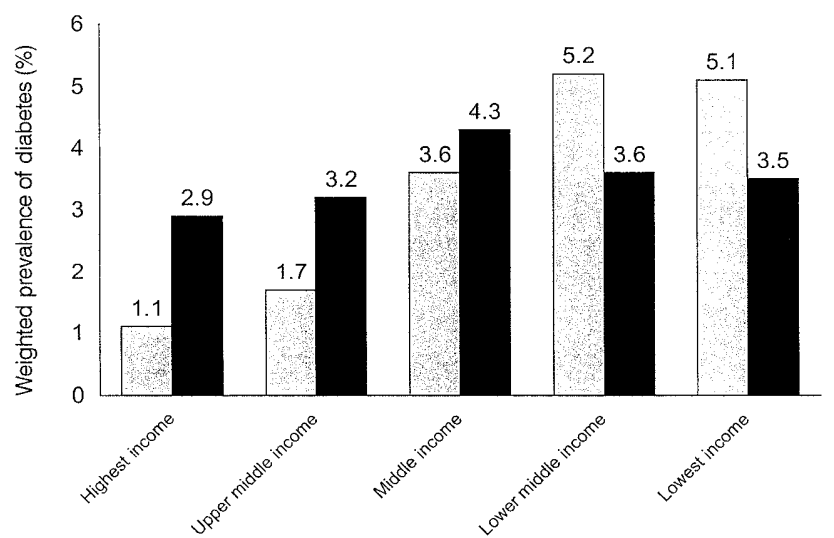

Fig. 7. Diabetes prevalence by income level and sex, Canada, 1996-1997 ( $n=54933)$; female $(\square)$, male $(\square)$

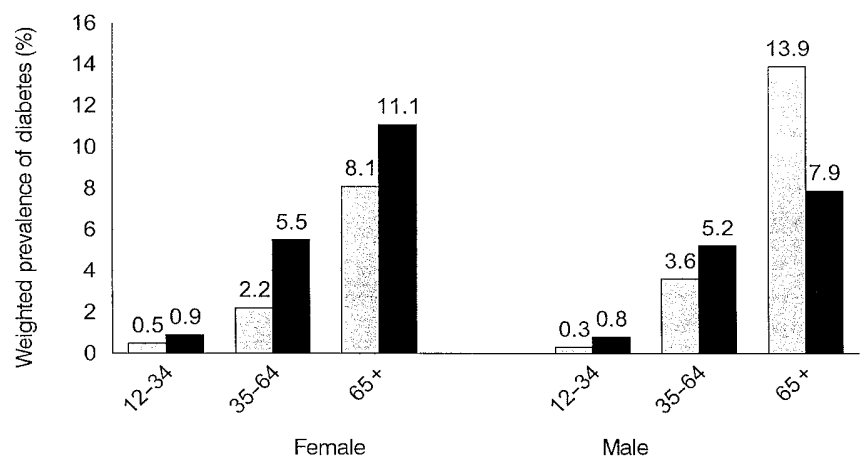

Fig. 8. Diabetes prevalence by income adequacy, age and sex, Canada, 1996-1997 ( $n=54933)$; adequacy $(\square)$, inadequacy (ם); Inadequate Income: family income $<\$ 15,000$ (1 or 2 persons); $<\$ 20,000$ (3 or 4 persons) $;<\$ 30,000(5+$ persons $)$

Marital status. Those widowed, divorced, and separated were initially found to have a higher prevalence of diabetes than the other marital status groups, whereas the single group had a low prevalence (Fig. 9; Table 1, univariate models). However, the observed effects of widowed or divorced or separated factors disappeared after adjusting for potential confounders such as age, sex and income (Table 1, multivariate model). In fact, single men and women had a higher prevalence of diabetes than those not single.

When trichotomized and studied by age and sex group, it was especially found that among 35 to 64 years old women, single women had a prevalence of diabetes $(3.4 \%)$ higher than the married, common law, or partner group $(2.4 \%)$, close to the prevalence of the widowed, divorced, or separated group (3.7\%) (Fig. 10).

Education. In both males and females, there was a general trend of an increase in the prevalence of diabetes with lower education. This was consistent in all age groups (data not shown). However, the observed effect of education level disappeared after adjusting for potential confounders such as age, sex and income $(\mathrm{OR}=1.00, p=0.99)$ (Table 1 , multivariate model).

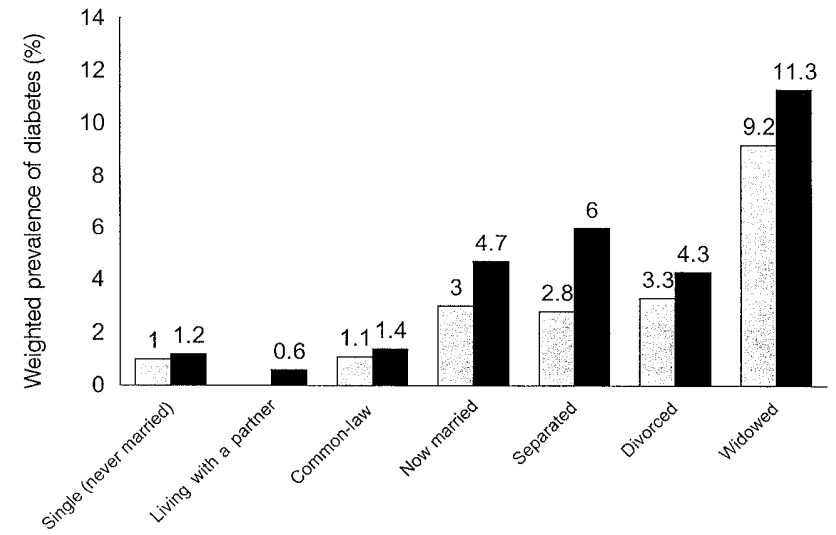

Fig.9. Diabetes prevalence by marital status and sex, Canada, 1996-1997 ( $n=69362)$; female $(\square)$, male $(\square)$

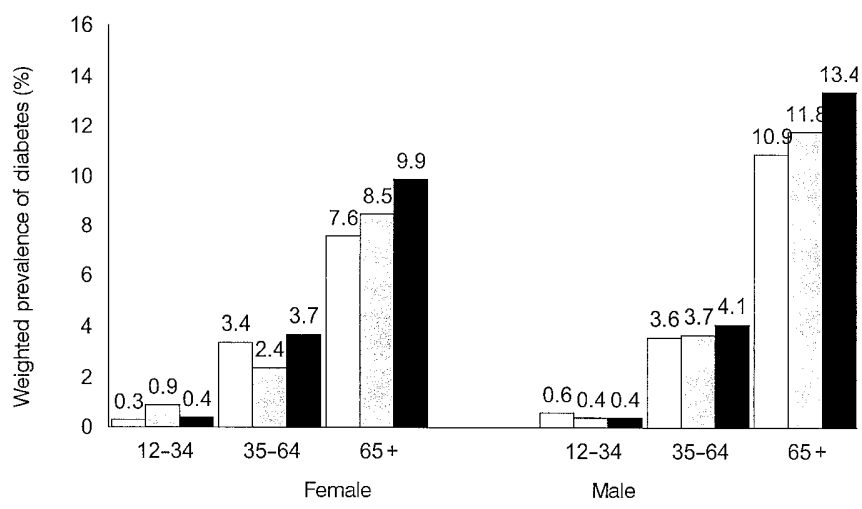

Fig. 10. Diabetes prevalence by marital status, age and sex, Canada, 1996-1997 ( $n=69362)$; single $(\square)$, married/common-law/partner $(\square)$, widowed/divorced/separated (

Rural or urban residence. The effect of rural or urban residence was inconsistent in different age and sex groups. For example, urban residence was associated with a higher prevalence of diabetes than rural residence in males 12 to 34 years of age, and 35 to 64 years of age, and in women 65 years or older. However, the reverse situation (urban residence had lower prevalence than rural residence) was found in men 65 or older, and in 35 to 64 year old women. After adjusting for potential confounders, urban residents were found to have a higher prevalence of diabetes $(\mathrm{OR}=1.27, p=0.01)$ (Table 1, multivariate model).

\section{Discussion}

Four major modifiable risk factors for diabetes have been identified in previous studies: obesity, body fat distribution, physical activity and dietary factors [7]. However, the extent of how these and other risk factors contributed to the prevalence of diabetes in Canada has not been systematically studied. Moreover, the effect of the risk factors could differ by age and sex categories. This paper shows various potential 
risk factors for diabetes by age and sex categories, and gives recommendations for prevention and control strategies for diabetes.

Age and sex. Our finding that prevalence of diabetes increased with age is consistent with studies in other countries [2]. Age is known to be an important determinant of diabetes since blood glucose concentrations tend to rise with age [8]. Regarding sex, while this study found a higher proportion of males $(54 \%$ males, $46 \%$ females) among Canadian patients with diabetes, studies in the United States found a higher proportion of females ( $42 \%$ males, $58 \%$ females) with diabetes [2]. This difference in Canada and in other countries remains to be confirmed. The higher prevalence of self-reported diabetes in males is unexpected and could be due to detection bias or other biases. Nevertheless, since age and sex are non-modifiable factors, there is little that can be done or recommended. Our study shows that it is desirable to consider the effects of various risk factors for diabetes, adjusted for age and sex.

Body mass index (BMI). Obesity, as measured by BMI, has been suggested to be a major modifiable risk factor for diabetes [9]. Our study has four findings on obesity which could have important implications for the prevention and control of diabetes for Canadian men and women.

First, we found that the prevalence of diabetes increased with obesity (BMI) in both males and females. This is consistent with the other published results. Those studies, including case-controls studies $[10,11,12,13]$, cross-sectional studies [14-17, 18], and cohort studies [19-23, 24-28, 29, 30, 31, 32-38], report a significant $(p<0.05)$ positive association between obesity and diabetes. One cohort study (1990) [39] failed to show a significant association $(\mathrm{OR}=1.21, p=0.44)$, probably due to its small cohort size $(n=474)$ and a small number of diabetic patients identified in the follow-up period $(n=28)$. A biological basis has also been proposed for the effect of obesity on diabetes: Obesity is partly genetically determined [40, 41] and partly an indicator of sugar imbalance, reflecting the difference between energy intake and energy expenditure [42-44]. Obesity affects glucose metabolism and therefore increases the risk of diabetes mellitus [9]. Therefore, it is recommended that both men and women should avoid becoming overweight.

Second, we found a differential effect of obesity on the prevalence of diabetes in males and females. For males, the prevalence of diabetes started to increase when BMI reached 27 (overweight category) but for females the prevalence of diabetes started to increase at a lower BMI level of 25 (some excess weight category). This is consistent with the other studies, which have shown that the per unit increase in BMI had a larger effect on the risk of diabetes among women than men. These studies include (1990) [48] $\left(\mathrm{RR}=1.54\right.$ per $3.3 \mathrm{~kg} / \mathrm{m}^{2}$ for women, $\mathrm{RR}=1.29$ per $3.3 \mathrm{~kg} / \mathrm{m}^{2}$ for men), (1995) [49] ( $\mathrm{RR}=2.35$ per $5 \mathrm{~kg} /$ $\mathrm{m}^{2}$ for women, $\mathrm{RR}=1.60$ per $5 \mathrm{~kg} / \mathrm{m}^{2}$ for men), (1995) [53] ( $\mathrm{RR}=1.65$ per $\mathrm{kg} / \mathrm{m}^{2}$ for women, $\mathrm{RR}=1.40$ per $\mathrm{kg} / \mathrm{m}^{2}$ for men), and (1997) [52] $\left(\mathrm{RR}=2.79\right.$ per $\mathrm{kg} / \mathrm{m}^{2}$ for women, $\mathrm{RR}=1.96$ per $\mathrm{kg} /$ $\mathrm{m}^{2}$ for men). Taken together these results suggest that perhaps two different criteria for obesity based on BMI should be used for males and females in future studies. Our study reconfirms the need, proposed (1998) [26] in a prospective cohort study of 654 men and women, to use different criteria to define obesity for women and men, at $25 \mathrm{~kg} / \mathrm{m}^{2}$ and $27 \mathrm{~kg} / \mathrm{m}^{2}$, respectively. In terms of prevention and control, this would mean that women should maintain their BMI below 25 (i. e. within the acceptable weight category), while men should maintain their BMI below 27 (i. e. acceptable weight and even some excess weight is alright, but not overweight). Or in other words, while the acceptable weight category for women is, based on a BMI of 20 to $25 \mathrm{~kg} / \mathrm{m}^{2}$, that for men should be redefined as 20 to $27 \mathrm{~kg} / \mathrm{m}^{2}$. Men on average have a larger body build than women and therefore obesity should be defined differently based on BMI.

Third, we initially found that insufficient weight was associated with an increased prevalence of diabetes among males but not among females. Although after adjusting for some potential confounding factors the effect of insufficient weight on diabetes disappeared it is possible that there exists a U-shaped dose-response relation between BMI and the risk of diabetes - both overweight and insufficient weight are associated with an increased prevalence of diabetes.

Fourth, the effect of increased weight on diabetes is consistent in all age groups. Previous studies have shown the effect of increased weight in men and women, but have not shown the effect of increased weight in different age groups. Our finding indicates that both men and women should avoid becoming overweight at all ages.

Energy expenditure. Independent of obesity, physical activity has been shown to have a beneficial effect on glucose metabolism [9]. Due to methodological problems, however, epidemiological evidence on physical activity and diabetes has been scarce. A number of cohort studies have shown an important beneficial effect of physical activity, after adjusting for BMI [30, 34, 45, 46, 47]. Other studies did not find an important beneficial effect of physical activity that is independent of BMI [20,23].

Of interest, however, is the finding of a U-shaped dose- response relation between physical activity and the risk of diabetes after adjusting for BMI, i.e. very low and very high levels of physical activity are 
associated with a high risk of diabetes, compared to moderate level of physical activity [18, 28, 29, 31, 48, 49]. In our study there was an increase in the prevalence of diabetes with a decrease in energy expenditure in both males and females, i.e. a decrease in the frequency, duration, and/or energy requirement of physical activity. When all ages were considered, this was a linear dose-response association and not a Ushaped association. However, this seemed to be due to a masking effect by age. When stratified by age, among males 12 to 64 years old, the physically active group had a somewhat higher prevalence of diabetes than the physically inactive group, with a greater difference being shown in males aged 12 to 34 years. A profiling of males in the 12 to 34 age group with diabetes indicates that approximately one third are active (this category includes active and moderate levels of energy expenditure) and two thirds are inactive. Of those active males with diabetes in this age group, approximately $80 \%$ are taking insulin for their diabetes, thus indicating a possible confounding by Type I (insulin-dependent) diabetes mellitus. Results of univariate and multivariate logistic regressions indicated that the situation of energy expenditure and diabetes is rather complicated. A U-shaped dose-response relation between physical activity and diabetes is possible and remains to be detected perhaps in future national health surveys.

Investigators (1993) [30] reported no sex difference for the effect of physical activity on diabetes (moderate vs high for women $\mathrm{OR}=1.17$, low vs high for women $\mathrm{OR}=1.31, p<0.05$; moderate vs high for men $\mathrm{OR}=1.13$, low vs high for men $\mathrm{OR}=1.28$, $p<0.05)$. In contrast others (1995) reported a beneficial effect of physical activity only among men $(\mathrm{OR}=0.41, p=0.03$, for each occurrence of planned leisure time physical activity in the past week) but not among women $(\mathrm{OR}=1.43, p=0.18)$. Together with our findings (a beneficial effect only in women and older men, but not men 12-64 years old), these results suggest that evidence of a sex difference for the effect of physical activity is inconsistent.

Smoking. Smoking has not been reported as a risk factor for diabetes but for diabetes associated complications such as heart diseases [1]. Smoking predisposes people with diabetes to heart disease, peripheral vascular disease, and lower extremity amputations. Our study indicated a small adverse effect of smoking on diabetes in men. This effect was not observed in women. For both men and women, former daily smokers had a higher prevalence of diabetes than daily smokers and non-smokers. This is probably the result of physicians, when diagnosing patients with diabetes, advising them to give up smoking. In multivariate logistic regression after adjusting for some potential confounders, currently daily smokers and former daily smokers were found to have a higher risk of diabetes than never smokers. Based on this, and that diabetic patients are at a high risk of developing complications such as heart diseases, it is recommended that they should give up smoking completely at the time of diagnosis of diabetes based on clinical practice guidelines.

Drinking. The role of habitual alcohol intake on glucose metabolism and the development of diabetes has been investigated only in a limited number of studies [9]. In a prospective study on men, liver function, used as an indicator of alcohol abuse, was an independent predictor of the 4-year diabetes risk [50]. In contrast, several other prospective studies showed no association between alcohol use and the incidence of diabetes [51, 52]. Alcohol consumption has been suggested as a possible independent risk factor for diabetes, because of its effect on the liver and pancreas and its additional calories resulting in increased weight $[53,54]$.

Our study found no effect of drinking on the prevalence of diabetes among men. However, there seems to be a beneficial effect among women who drink (occasional, i.e. less than one drink a month; and regular, i.e. a drink at least once a month) in reducing the prevalence of diabetes compared to abstainers, especially in the 12 to 64 year age group. In this study, the regular drinkers have been defined too broadly, as anyone who drinks at least once a month is a regular drinker. This has reduced the ability of the study to identify the effect of heavy drinking on diabetes.

The fact that both male and female former drinkers (did not have a drink in the last 12 months) were associated with a higher prevalence of diabetes could be an artefact, for example, due to a reversed causation - patients follow the recommendation by their physicians and give up drinking at the time of diagnosis. Currently no recommendations could be made for drinking as there is insufficient evidence of an effect.

Income. It has been suggested that higher income groups, usually as a result of their higher level of education and higher social standing, had higher diabetes prevalence in developing countries [10]. This could be the result of a true effect through a greater access to food, or an artifact due to a greater access to medical care. However, others have shown that lower income, education, and social class are associated with increased prevalence of diabetes in affluent societies [55].

Our study indicated a trend of increased prevalence of diabetes towards the lower end of income adequacy, especially in females. It is therefore recommended that in Canada diabetes prevention and control strategies should be targeted for low income groups, especially low income females.

Marital status. Marital status has not been described previously as a risk factor for diabetes. Our study ini- 
tially found that the widowed, divorced, or separated groups had a higher prevalence of diabetes than the other marital status groups, while the single group had a low prevalence. However, after adjusting for age and other potential confounding factors, the widowed, divorced, or separated groups were found to have a lower risk of diabetes. This indicates confounding by factors such as age, in that the average age of those in the widowed, divorced and separated categories is higher than the average age in the other marital categories. After using multivariate techniques, persons who are single were found to have the highest risk of diabetes.

We found that women in the age group of 35 to 64 years who were still single had a higher prevalence of diabetes $(3.4 \%)$ than the married, common-law, partner group $(2.4 \%)$ of the same age, which was close to the prevalence of the widowed, divorced, or separated group $(3.7 \%)$. This was not observed among men of 35 to 64 years old. Closer investigation of the risk factor profiles of singles women in the 35 to 64 age group indicated that the mean age and BMI of this group is similar to those of women in other marital status groups in the same age range. Thus, the higher prevalence of diabetes among single 35 to 64 year old women cannot be attributed to higher levels of these risk factors. In the United States, it was found that at age 18 to 44 years, women and men with diabetes were less likely than women and men without diabetes, respectively, to be single, but at age 45 to 64 years, women and men with diabetes were more likely than women and men without diabetes, respectively, to be single [56].

Given that the univariate results are completely opposite to the results of the multivariate analysis and that in stratified analysis only one group (female, single, 35-64 years old) seems to support this finding from the multivariate model whereas the other groups showed a clear opposite trend, it is not possible to make any recommendations concerning marital status.

Education. Our data initially showed a high prevalence of diabetes among those with lower education, which disappeared in multivariate analysis. We therefore recommend that diabetes prevention and control strategies should be targeted for people at all education levels.

Rural or urban residence. Rural residents have been shown to have lower prevalence of diabetes than urban residents $[57,58]$. This could be due to the beneficial effect of physical activity, a less sedentary lifestyle, being less obese, and a lower level of stress among rural residents [2]. Our study, however, did not show a consistent effect of rural residence in different age and sex groups. We therefore recommend that diabetes prevention and control strategies should be equally targeted for rural and urban areas.
Limitations of this study. First, this study, due to the design of the NPHS, was not able to differentiate between the various types of diabetes, especially Type I and Type II (non-insulin-dependent) diabetes mellitus. It is expected that most of the patients with diabetes in the NPHS would be Type II diabetic patients, given the distribution of different types of patients diagnosed with diabetes cases in the general population. For example, since our study participants were older than 12 years, most would likely be Type II diabetic patients but this cannot be confirmed. Second, other risk factors have been described, such as ethnicity, genetic factors, diet (dietary carbohydrate and fibre, dietary fat), duration of obesity, body fat distribution, parity and pregnancy effects, thinness at birth, which could affect the prevalence of diabetes [2]. However, these risk factors were not studied due to lack of relevant information or adequate sample sizes in the NPHS. Third, although the analysis was stratified by age and sex, and controlled for some other potential confounder variables through multiple logistic regression, there could be other confounders which have not been adjusted for. Fourth, as this was a cross-sectional study, it was not able to determine causal associations. For example, lower physical activity could have been reported after diagnosis of diabetes and this could have been the result of diabetes rather than its cause. Fifth, the NPHS, being a questionnaire-based survey, could underestimate the true prevalence of diabetes, since there is about one undiagnosed case for each known diabetic person $[1,2]$.

Recommendations. Based on our in-depth analysis of the relations between prevalence of diabetes and a number of potential risk factors, we suggest a number of recommendations to public health agencies:

First, women and men of all ages should avoid becoming overweight. Women should maintain their BMI below $25 \mathrm{~kg} / \mathrm{m}^{2}$ and men should maintain their BMI below $27 \mathrm{~kg} / \mathrm{m}^{2}$.

Second, women and men of all ages should maintain a moderate level of physical activity.

Third, patients with diabetes should give up smoking completely at the time of diagnosis.

Fourth, diabetes prevention and control strategies should be targeted for women in low income groups.

\section{References}

1. Health Canada (1999) Diabetes in Canada: National statistics and opportunities for improved surveillance, prevention, and control. Catalogue No. H49-121/1999. Ottawa: Laboratory Centre for Disease Control, Bureau of CardioRespiratory Diseases and Diabetes

2. Harris MI (1995) Diabetes in America. In: National Diabetes Data Group. 2nd edn. NIH Publication No. 95-1468, 
National Institutes of Health, National Institute of Diabetes and Digestive and Kidney Diseases, Bethesda, pp 1-13

3. Centers for Disease Control and Prevention (1997) National diabetes fact sheet: National estimates and general information on diabetes in the United States. U.S. Department of Health and Human Services, Centers for Disease Control and Prevention, Atlanta

4. 1996-97 NPHS Public Use Microdata Documentation. (1997) Statistics Canada, Ottawa

5. Tambay JL, Catlin G (1995) Sample design of the National Population Health Survey. Health Reports 7: 29-38

6. Willett WC, Dietz WH, Colditz GA (1999) Guidelines for healthy weight. New Engl J Med341: 427-434

7. Haffner SM (1998) Epidemiology of type 2 diabetes: risk factors. Diabetes Care 21 [Suppl 3]: C3-C6

8. West KM (1978) Epidemiology of diabetes and its vascular lesions. Elsevier Biomedical Press, New York

9. Rewers M, Hamman RF (1995) Risk factors for non-insulin-dependent diabetes. In: National Diabetes Data Group. Diabetes in America $2^{\text {nd }}$ Edn. NIH Publication No. 95-1468. National Institutes of Health, National Institute of Diabetes and Digestive and Kidney Diseases, Bethesda, pp 179-220

10. Himsworth HP, Marshall EM (1935) The diet of diabetes prior to the onset of disease. Clin Sci (Colch) 2: 95-115

11. Baird JD (1972) Diet and the development of clinical diabetes. Acta Diabetol Lat 9[Suppl 1]: 621-639

12. Harris MI, Hadden WC, Knowler WC et al. (1987) Prevalence of diabetes and impaired glucose tolerance and plasma glucose levels in US population aged 20-74 years. Diabetes 36: 523-534

13. Woo J, Ho SC, Donnan SP (1989) Risk factors in non-insulin dependent diabetes mellitus in elderly Chinese in Hong Kong. Public Health 103: 57-66

14. Kannel WB, Gordon T, Castelli WP (1999) Obesity, lipids, and glucose intolerance: The Framingham Study. Am J Clin Nutr 32: 1238-1245

15. Bonham GS, Brock DB (1985) The relationship of diabetes with race sex, and obesity. Am J Clin Nutr 41: 776-783

16. Chen MK, Lowenstein FW (1986) Epidemiology of factors related to self-reported diabetes among adults. Am J Prev Med 2: 14-19

17. Seidell JC, De Groot CPMG, van Sonsbeek JLA et al.(1986) Associations of moderate and severe overweight with self reported illness and medical consumption in Dutch adults. Am J Public Health 76: 264-269

18. Tai TY, Chuang LM, Wu HP, Chen CJ (1992) Association of body build with non-insulin- dependent diabetes mellitus and hypertension among Chinese adults: a 4-year follow-up study. Int J Epidemiol 21: 511-517

19. Haffner SM, Miettinen H, Stern MP (1997) Are risk factors for conversion to NIDDM similar in high and low risk populations? Diabetologia 40: 62-66

20. Young TK, Harris SB (1994) Risk of clinical diabetes in a northern Native Canadian cohort. Arctic Med Res 53: 64-70

21. Carey VJ, Walters EE, Colditz GA (1997) Body fat distribution and risk of non-insulin-dependent diabetes mellitus in women. The Nurses' Health Study. Am J Epidemiol 145: 614-619

22. Eriksson KF, Lindgarde F (1996) Poor physical fitness, and impaired early insulin response but late hyperinsulinaemia, as predictors of NIDDM in middle-aged Swedish men. Diabetologia 39: 573-579

23. Njolstad I, Arnesen E, Lund-Larsen PG (1998) Sex differences in risk factors for clinical diabetes mellitus in a gener- al population: a 12-year follow-up of the Finnmark Study. Am J Epidemiol 147: 49-58

24. Cassano PA, Rosner B, Vokonas PS, Weiss ST (1992) Obesity and body fat distribution in relation to the incidence of non-insulin-dependent diabetes mellitus. A prospective cohort study of men in the normative aging study. Am J Epidemiol 136: 1474-1486

25. Chan JM, Rimm EB, Colditz CA, Stampfer MJ, Willet WC (1994) Obesity, fat distribution, and weight gain as risk factors for clinical diabetes in men. Diabetes Care 17: 961-969

26. Chou P, Li CL, Wu GS, Tsai ST (1998) Progression to type 2 diabetes among high-risk groups in Kin-Chen, Kinmen. Exploring the natural history of type 2 diabetes. Diabetes Care 21: 1183-1187

27. Feskens EJ, Bowles CH, Kromhout D (1991) Carbohydrate intake and body mass index in relation to the risk of glucose intolerance in an elderly population. Am J Clin Nutr 54: 136-140

28. Gurwitz JH, Field TS, Glynn RJ et al. (1994) Risk factors for non-insulin-dependent diabetes mellitus requiring treatment in the elderly. J Am Geriatr Soc 42: 1235-1240

29. Helmrich SP, Ragland DR, Leung AB, Paffenbarger RS Jr (1991) Physical activity and reduced occurrence of non-insulin-dependent diabetes mellitus. N Engl J Med 325: 147-152

30. Lipton RB, Liao Y, Cao G, Cooper RS, McGee D (1993) Determinants of incident non-insulin- dependent diabetes mellitus among blacks and whites in a national sample. The NHANES I Epidemiologic Follow-up Study. Am J Epidemiol 138: 826-839. (Published erratum appears in Am J Epidemiol 1994, 139: 964)

31. Manson JE, Nathan DM, Krolewski AS, Stampfer MJ, Willet WC, Hennekens CH (1992) A prospective study of exercise and incidence of diabetes among US male physicians. JAMA 268: 63-67

32. McPhillips JB, Barrett-Connor E, Wingard DL (1990) Cardiovascular disease risk factors prior to the diagnosis of impaired glucose tolerance and non-insulin-dependent diabetes mellitus in a community of older adults. Am J Epidemiol 131: 443-453

33. Monterrosa AE, Haffner SM, Stern MP, Hazuad HP (1995) Sex differences in life style factors predictive of diabetes in Mexican-Americans. Diabetes Care 18: 448-456

34. Perry IJ, Wannamethee SG, Walker MK, Thomson AG, Whincup PH, Shaper AG (1995) Prospective study of risk factors for development of non-insulin dependent diabetes in middle-aged British men. BMJ 310: 560-564

35. Shaten BJ, Smith GD, Kuller LH, Neaton JD (1993) Risk factors for the development of type II diabetes among men enrolled in the usual care group of the Multiple Risk Factor Intervention Trial. Diabetes Care 16: 1331-1339

36. Wang SL, Pan WH, Hwu CM et al. (1994) Incidence of NIDDM and the effects of gender, obesity and hyperinsulinaemia in Taiwan. Diabetologia 40: 1431-1438

37. Warne DK, Charles MA, Hanson RL et al. (1995) Comparison of body size measurements as predictors of NIDDM in Pima Indians. Diabetes Care 18: 435-439

38. Wei M, Gaskill SP, Haffner SM, Stern MP (1997) Waist circumference as the best predictor of non-insulin-dependent diabetes mellitus (NIDDM) compared to body mass index, waist/hip ratio and other anthropometric measurements in Mexican Americans - a 7-year prospective study. Obes Res 5: 16-23

39. Haffner SM, Stern MP, Mitchell BD, Hazuda HP, Patterson JK (1990) Incidence of type II diabetes in Mexican Americans predicted by fasting insulin and glucose levels, obesity, and body-fat distributions. Diabetes 39: 283-288 
40. Bouchard C, Tremblay A, Després J-P et al. (1990) The response to long-term overfeeding in identical twins. N Engl J Med 322: 1477-1482

41. Stunkard AJ, Harris JR, Pedersen NL et al. (1990) The body-mass index of twins who have been reared apart. N Engl J Med 322: 1483-1487

42. Danforth E (1985) Diet and obesity. Am J Clin Nutr 41: 1132-1145

43. Bray GA (1987) Obesity - A disease of nutrient or energy balance? Nutr Rev 45: 33-43

44. Kromhout D, Saris WHM, Horst CH (1988) Energy intake, energy expenditure, and smoking in relation to body fatness: The Zutphen Study. Am J Clin Nutr 4: 668-674

45. Burchfiel CM, Hamman RF, Marshall JA, Baxter J, Kahn LB, Amirani JJ (1990) Cardiovascular risk factors and impaired glucose tolerance: the San Luis Valley Diabetes Study. Am J Epidemiol 131: 57-70

46. Hara H, Egusa G, Yamakido M (1996) Incidence of non-insulin-dependent diabetes mellitus and its risk factors in Japanese-Americans living in Hawaii and Los Angeles. Diabet Med 13[Suppl 6]:S133-S142

47. Lynch J, Helmrich SP, Lakka TA et al. (1996) Moderately intense physical activities and high levels of cardiorespiratory fitness reduce the risk of non-insulin-dependent diabetes mellitus in middle-aged men. Arch Intern Med 156: $1307-1314$

48. James SA, Jamjoum L, Raghunathan TE, Strogatz DS, Furth ED, Khazanie PG (1998) Physical activity and NIDDM in African-Americans. The Pitt County Study. Diabetes Care 21: 555-562

49. Manson JE, Rimm EB, Stampfer MJ et al. (1991) Physical activity and incidence of non-insulin-dependent diabetes mellitus in women. Lancet 338: 774-778

50. Papoz L, Eschwege E, Warnet J-M et al. (1982) Incidence and risk factors of diabetes in the Paris Protective Study
(GREA). In: Eschwege E (ed) Advances in diabetes epidemiology. Wlsevier, Amsterdam pp 113-122

51. Feskens EJM, Kromhout D Cardiovascular risk factors and the 25-year incidence of diabetes mellitus: The Zutphen Study. Am J Epidemiol 130: 1101-1108

52. Stampfer MJ, Colditz GA, Willett EC et al. (1998) A prospective study of moderate alcohol drinking and risk of diabetes in women. Am J Epidemiol 128: 549-558

53. Colditz GA, Giovannucci E, Rimm EB et al. (1991) Alcohol intake in relation to diet and obesity in women and men. Am J Clin Nutr 54: 49-55

54. Rissanen AM, Heliovaara M, Knekt P, Reunanen A, Aromaa A (1991) Determinants of weight gain and overweight in adult Finns. Eur J Clin Nutr 45: 419-430

55. Hamman RF (1983) Diabetes in affluent societies. In: Mann JI, Pyorala K, Teuscher A (eds) Diabetes in epidemiologic perspective. Churchill Livingstone, Edinburgh pp $7-42$

56. Cowie CC, Eberhardt MS (1995) Sociodemographic characteristics of persons with diabetes. In: National Diabetes Data Group. Diabetes in America. 2nd edn. NIH Publication No. 95-1468. National Institutes of Health, National Institute of Diabetes and Digestive and Kidney Diseases, Bethesda $\mathrm{p} 92$

57. Zimmet P, Faaiuso S, Ainuu J, Whitehouse S, Milne B, DeBoer W (1981) The prevalence of diabetes in the rural and urban Polynesian population of Western Samoa. Diabetes 30: 45-51

58. Bennett PH, Bogardus C, Tuomilehto J, Zimmet P (1992) Epidemiology and natural history of NIDDM: Non-obese and obese. In: Alberti KGMM, DeFronzo RA, Keen H, Zimmer P, (eds) International Textbook of Diabetes. John Wiley \& Sons, Chichester pp 148-176 